\title{
Acesso à justiça: a tutela coletiva de direitos individuais homogêneos e dos direitos da personalidade
}

\author{
Access to justice: collective protection of homogeneous individual \\ rights and personality rights
}

\author{
Daniela Menengoti Gonçalves Ribeiro ${ }^{l}$ \\ Fernando Navarro Vince ${ }^{2}$ \\ João Paulo Gomes Netto ${ }^{3}$
}

\begin{abstract}
RESUMO
Este trabalho analisa os entraves do acesso à justiça, demonstrando que os desafios se estendem aos direitos da personalidade, em especial pelas constantes transformações da sociedade que inevitavelmente refletem na personalidade do sujeito. Como pergunta de partida, questiona a natureza dos direitos individuais homogêneos e os instrumentos legislativos para a tutela conjunta de tais direitos. Ao se valer de raciocínio hipotético-dedutivo, por meio de pesquisa bibliográfica e documental, descritiva e exploratória, o artigo conclui que a fim de se dar efetividade à justiça, há a possibilidade da defesa coletiva de direitos individuais homogêneos e, portanto, possível também para os direitos da personalidade.
\end{abstract}

\section{PALAVRAS-CHAVE:}

Acesso à Justiça; efetividade; direitos individuais homogêneos; direitos da personalidade.

\begin{abstract}
This paper analyzes the barriers to access to justice, demonstrating that the challenges extend to personality rights, especially by the constant transformations of society that inevitably reflect on the personality of the subject. As a starting question, it questions the nature of homogeneous individual rights and the legislative instruments for joint protection of such rights. By using hypothetical-deductive reasoning through bibliographic and documentary, descriptive and
\end{abstract}

\footnotetext{
${ }^{1}$ Professora do Programa de Mestrado em Ciências Jurídicas e da graduação em Direito do Centro Universitário de Maringá (UNICESUMAR). Coordenadora/Líder dos Grupos de Pesquisa (CNPq): Instrumentos jurisdicionais de efetivação dos direitos da personalidade e Coordenadora/Líder do Grupos de Pesquisa (CNPq): Internacionalização do direito: dilemas constitucionais e internacionais contemporâneos. Pesquisadora do Instituto Cesumar de Ciência, Tecnologia e Inovação (ICETI). Doutora em Direito-Relações Econômicas Internacionais pela Pontifícia Universidade Católica de São Paulo (PUC/SP) com período de pesquisa (doutorado sanduíche) na Université Paris 1 - Panthéon-Sorbonne, França.

2 Mestre em Ciência Jurídicas Centro Universitário de Maringá (UNICESUMAR). Especialista em Direito do Estado pela Universidade Estadual de Londrina (UEL). Graduado em Direito pela Universidade Estadual de Londrina (UEL). Docente de Ensino Superior desde 2011. Professor de Direito Constitucional e Processual Civil dos programas de Pós-graduação Lato Sensu (Especialização) do Instituto de Direito Constitucional e Cidadania (IDCC). Membro do Grupo de Pesquisa (CNPq) Internacionalização do direito: dilemas constitucionais e internacionais contemporâneos. Advogado. E-mail: fernandonavarrovince@gmail.com.

${ }^{3}$ Mestrando em Direitos da Personalidade pelo Centro Universitário de Maringá (UNICESUMAR). Membro do Grupo de Pesquisa (CNPq): Instrumentos jurisdicionais de efetivação dos direitos da personalidade. Advogado. E-mail: joaonetto.adv@gmail.com.
} 
exploratory research, the article concludes that in order to give effectiveness to justice, there is the possibility of collective defense of homogeneous individual rights and, therefore, also possible. for personality rights.

KEYWORDS:

Access to justice; effectiveness; homogeneous individual rights; personality rights.

\section{INTRODUÇÃO}

O presente estudo trata do acesso à justiça como direito e garantia fundamental previsto na Constituição Federal, os empecilhos e as soluções para a efetividade do acesso à justiça. Não se pretende exaurir a análise de todas as barreiras inerentes ao acesso à justiça, mas sim de trazer os principais obstáculos impeditivos para a concretização deste direito, bem como despertar a reflexão sobre a possibilidade de se utilizar de vias processuais coletivos para a garantia de direitos da personalidade, buscando, assim, a aplicação dos meios judiciais de efetivação.

A propósito dos direitos da personalidade, o art. $5^{\circ}$ da Constituição Federal e os artigos $1^{\mathrm{o}}$ ao 21 do Código Civil brasileiro os fundamentem juridicamente como aqueles direitos subjetivos da pessoa de defender o que é próprio, seu: a vida, a integridade, a liberdade, a sociabilidade, a honra, a imagem, a privacidade, a autoria e outros mais, sempre em respeito aos princípio constitucionais de garantia dos direitos fundamentais individuais, principalmente, o princípio da dignidade humana.

No entanto, em que pese essa taxatividade, as constantes transformações sociedade revela haver sempre novas instâncias concernentes à personalidade do sujeito, não previstas nem previsíveis pelo legislador, de modo que estes interesses precisam ser tidos como uma categoria aberta.

Assim, a identificação taxativa dos direitos da personalidade opõe-se à consideração de que a pessoa humana - e, portanto, sua personalidade - se configura como um valor unitário, 
sendo ainda necessário o reconhecimento, pelo ordenamento jurídico, de uma cláusula geral que consagre a proteção integral da personalidade. ${ }^{4}$ Reconhecendo, assim, tais mudanças, busca-se demonstrar que a efetividade dos direitos da personalidade, também pode se pelo tratamento dos direitos individuais de forma coletiva.

Para o estudo, utilizou-se do raciocínio hipotético-dedutivo, por meio de pesquisa bibliográfica e documental, descritiva e exploratória, dividindo o texto em três partes. De início foram investigados os aspectos concernentes ao sentido de justiça, com o objetivo de romper com o aspecto meramente simbólico do acesso à justiça e caracterizando-o como um direito fundamental e um meio de garantia dos direitos. Após, analisa-se os empecilhos e as soluções para a efetividade do acesso à justiça. Por fim, sustenta-se que por meio de instrumentos jurídicos já existentes e análise da natureza jurídica dos direitos individuais homogêneos, é possível a defesa coletiva de direitos da personalidade.

\section{ACESSO À JUSTIÇA}

O Estado se caracteriza como organização política da sociedade, e uma ordem jurídica soberana. Contemporaneamente, o Estado tem se destacado por seu caráter de instrumentalidade, ou seja, é o meio útil de concretizar objetivos da sociedade, bem como, a promoção do bem comum e do intervencionismo ${ }^{5}$.

Os elementos que caracterizam o Estado Contemporâneo, em que pese conexos, possuem distintas variações doutrinárias, dentre os quais destacam-se os princípios de justiça social, de instrumentalidade e de uma ordem jurídica legítima de uma lado, e de outro, a corrente que entende como elementos, as garantias relativas à liberdade e a participação popular nas decisões do poder público devem ser asseguradas no Estado Democrático. ${ }^{6}$ Nesse sentido, a definição de 'Estado' não é universal, uma vez que, “depende sempre de atribuição de sentido

\footnotetext{
${ }^{4}$ MORAES, Maria Celina Bodin. Ampliando os direitos da personalidade. In: 20 anos da Constituição Cidadã de 1988: efetivação ou impasse institucional. (Org.) José Ribas Vieira. Rio de Janeiro: Forense, 2008. Disponível em: https://www.academia.edu/9689598/Ampliando_os_direitos_da_personalidade. Acesso em: 29 mar. 2019.

${ }^{5}$ MATTOS. Fernando Pagani. Acesso à justiça: um princípio em busca da efetivação. Curitiba: Juruá, 2009. p. 61

${ }^{6}$ MATTOS. Fernando Pagani. Acesso à justiça: um princípio em busca da efetivação. Curitiba: Juruá, 2009. p. 61
} 
por parte daquele que se serve da expressão indicando qual o fato do mundo fenomênico ela está denotando" 7

Não obstante, o Poder Judiciário faz parte do próprio Estado enquanto instituição ligado a seu funcionamento. Tal entendimento remonta a obra o Espírito das Leis, de Montesquieu, na qual defendeu que todo bom governo se devia reger pelo princípio de divisão dos poderes: legislativo, executivo e judiciário.

A ideia de separação dos poderes, que traduziu o conceito de limitação do poder estatal, é essencial para a implementação das liberdades individuais e fortalecimento do Estado Democrático de Direito.

Segundo Celso Lafer, existe uma relação direta entra a teoria de Montesquieu e os princípios que inspiram a tutela dos direitos fundamentais do homem no constitucionalismo.

Com efeito, a passagem do Estado absolutista para o Estado de Direito transita pela preocupação do individualismo em estabelecer limites ao abuso de poder do todo em relação ao indivíduo. Estes limites, vistos como necessários para que as individualidades possam ser livres, resultariam da divisão dos poderes, na lição clássica de Montesquieu - que tem suas raízes na teoria do governo misto, combinada com uma declaração de direitos, ambas expressas num texto escrito: a constituição. ${ }^{8}$

Com isso, pode-se afirmar que é função do poder judiciário tendente a assegurar a aplicação do direito de forma igualitária na sociedade, a fim de promover a pacificação social e a educação, garantindo o livre exercício dos direitos, sendo, outrossim, que o ordenamento jurídico foi criado para garantir a efetivação dos direitos individuais, coletivos e difusos de toda a sociedade. Por fim, verifica-se a ligação entre a estrutura do Estado, a sociedade política, e acesso à justiça, e, por consequência, a imprescindível criação de mecanismos eficazes de acesso ao poder judiciário.

$\mathrm{O}$ acesso à justiça é garantia fundamental esculpido no artigo $5^{\circ} \mathrm{XXXV}$ da Constituição Federal, o qual preceitua que "a lei não excluirá da apreciação do Poder Judiciário lesão ou ameaça a direito". ${ }^{9}$ É, pois, a efetivação da noção de "justiça", que está intimamente ligada a

\footnotetext{
${ }^{7}$ BRANDÃO, Paulo de Tarso. Ações Constitucionais: novos direitos e Acesso à Justiça. Florianópolis: Habitus, 2001. p. 25-26.

${ }^{8}$ LAFER, Celso. A reconstrução dos direitos humanos: um diálogo com o pensamento de Hannah Arendt. São Paulo: Companhia das Letras, 2009. p. 122-123.

${ }^{9}$ BRASIL. Constituição (1988). Constituição da República Federativa do Brasil. Brasília, DF: Senado Federal.
} 
seu acesso, pois de nada adiantaria seu asseguramento sem uma maneira hábil de torná-la aplicável e possível. ${ }^{10}$

O termo "acesso à justiça" possui diversas conceituações denotando-se, desde o acesso aos aparelhos jurídicos do poder judiciário ou acesso aos valores e direitos fundamentais do ser humano, no entanto, Paulo de Tarso Brandão e Douglas Roberto Martins alerta que embora a previsão constitucional aparentemente cuide do acesso ao Poder Judiciário, não se pode negligenciar que este compõe parte significativa daquela. ${ }^{11}$

A assistência jurídica é um conceito maior que a mera assistência judiciária devendo ser entendido como qualquer auxílio jurídico aos necessitados. ${ }^{12}$ Nesse sentido, Pontes de Miranda assegura que:

[...] O benefício da justiça gratuita é direito à dispensa provisória de despesas, exercível em relação jurídica processual, perante o juiz que promete a prestação jurisdicional. É instituto de direito pré-processual. A assistência judiciária é organização estatal, ou paraestatal, que tem por fim, ao lado da dispensa provisória das despesas, a indicação de advogado. ${ }^{13}$

Mauro Cappelletti e Bryant Garth, reconhecem que o termo possui difícil definição, porém delimitam duas finalidades básicas do sistema jurídico: a de ser acessível a todos a fim de reivindicar seus direitos e resolver litígios, e a de produzir resultados justos:

\begin{abstract}
A expressão "acesso à Justiça" é reconhecidamente de difícil definição, mas serve para determinar duas finalidades básicas do sistema jurídico — o sistema pelo qual as pessoas podem reivindicar seus direitos e/ou resolver seus litígios sob os auspícios do Estado que, primeiro deve ser realmente acessível a todos; segundo, ele deve produzir resultados que sejam individual e socialmente justos. Nosso enfoque, aqui, será primordialmente sobre o primeiro aspecto, mas não poderemos perder de vista o segundo. Sem dúvida, uma premissa básica será a de que a justiça social, tal como desejada por nossas sociedades modernas, pressupõe o acesso efetivo. ${ }^{14}$
\end{abstract}

\footnotetext{
${ }^{10}$ SILVA, Adriana dos Santos. Acesso à justiça e arbitragem: um caminho para a crise do judiciário. São Paulo: Manole, 2005. p. 90.

${ }^{11}$ BRANDÃO, Paulo de Tarso; MARTINS, Douglas Roberto. Julgamento antecipado da lide, direito à prova e Acesso à Justiça. In: ROSA, Alexandre Moraes da (Org.). Para um direito democrático: diálogos sobre paradoxos. São Jose: Conceito, 2006. p. 09.

12 RAMOS, Glaugo Gumerato. Realidade e perspectivas da assistência jurídica ao necessitado no Brasil. Revista do Advogado. São Paulo. n. 59, 2000. p. 73.

${ }^{13}$ PONTES DE MIRANDA apud MORAES, Humberto Pena de; SILVA, José Fontenelle Teixeira da. Assistência judiciária: sua gênese sua história e a função protetiva do Estado. 2. ed. Rio de Janeiro: Líber Juris, 1984. p. 94.

${ }^{14}$ CAPPELLETTI, Mauro; GARTH, Bryant. Acesso à justiça. Tradução de Ellen Gracie Northfleet. Porto Alegre: Fabris, 2002. p.8.
} 
O dever de assegurar o acesso à justiça não se limita a distribuição do feito, mas também a manutenção de tribunais estatais à população, bem como o acesso a um complexo sistema de informação legal e patrocínio de defesa dos interesses aos hipossuficientes que possibilite a igualdade de todos e, ainda, uma justiça célere em prol do jurisdicionado. ${ }^{15} \mathrm{Ou}$ seja, a efetividade do acesso à justiça depende da igualdade entre os litigantes. ${ }^{16}$

O procedimento jurisdicional rompe os obstáculos e inicia o processo de facilitação da obtenção da justiça, porém, sua efetivação engloba meios adequados v.g. materiais, financeiros, etc., o desenvolvimento do procedimento para diminuir custos e duração do processo, entre outros. $^{17}$

Verifica-se, que junto com as constantes implementações de novos tipos de relações sociais vem a evolução do acesso à justiça que deve ser entendida como fenômeno social ligado à busca dos ideais de justiça no tempo e no espaço através dos mais diversos tipos de conflitos, sempre com vistas a uma proteção dos direitos individuais e coletivos garantidos na Lei Maior. Esses diversos tipos de conflitos nascem de uma sociedade multicultural, onde cada grupo social busca a proteção de seus direitos fundamentais. ${ }^{18} \mathrm{O}$ acesso à justiça, constitucionalmente consagrado, é o meio do qual os demais direitos fundamentais podem ser assegurados ${ }^{19}$, para tanto, diversos empecilhos necessitam serem superados para sua efetivação, consoante passamos a expor.

\footnotetext{
${ }^{15}$ MARTINS, Pedro Batista. Acesso à justiça. In: MARTINS, Pedro Batista et al. Aspectos fundamentais da lei da arbitragem. Rio de Janeiro: Forense, 1999. p. 4.

${ }^{16}$ OLIVEIRA, José Sebastião de; ROSA, Angélica Ferreira. O acesso à justiça: realidade ou ficção, neste início de século XXI? Revista Jurídica Cesumar - Mestrado, v. 16, n. 2, maio/ago. 2016 - ISSN 1677-6402. p. 566.

${ }^{17}$ OLIVEIRA, José Sebastião de; ROSA, Angélica Ferreira. O acesso à justiça: realidade ou ficção, neste início de século XXI? Revista Jurídica Cesumar - Mestrado, v. 16, n. 2, maio/ago. 2016 - ISSN 1677-6402. p. 566

${ }^{18}$ JABORANDY, Clara Cardoso Machado; NEJAIM, América Cardoso Barreto Lima. O diálogo da mediação: uma garantia de acesso à ordem jurídica humanizada. Revista Juris Poiesis, Rio de Janeiro. Vol. 21, n. 26, 2018, p. 155. Disponível em http://periodicos.estacio.br/index.php/jurispoiesis/article/viewFile/5737/47965109. Acesso em: 30 jul. 2019.

${ }^{19}$ PAROSKI, Mauro Vasni. Direitos fundamentais e acesso à justiça na constituição. São Paulo: LTr, 2008, p. 138
} 


\title{
2.1 Entraves e efetivação da Justiça
}

Inúmeros são os fatores apontados como impeditivos para o acesso à justiça. Para Boaventura de Sousa Santos, são três os obstáculos ao acesso à justiça, quais sejam, as de ordem econômica, social e cultural ${ }^{20}$. Neste sentido, destaca-se as "custas judiciais" como primeiro obstáculo, uma vez que os litigantes devem arcar com os custos necessários ao deslinde da causa, dentre os quais honorários e custas judiciais. ${ }^{21}$

A relação entre o valor da causa e o custo elevado do litígio são, grande parte das vezes, desproporcionais, e a justiça, que já é onerosa para as pessoas comuns, tornando-se ainda mais cara para os cidadãos economicamente mais fracos. ${ }^{22}$ Portanto, aqueles que possuem recursos financeiros consideráveis, levam vantagens como litigantes, pois podem pagar para proporem ações ou para se defenderem, podendo ainda, suportar longos litígios e argumentos mais eficientes. $^{23}$

Fernando Pagani Mattos lembra que a situação se agrava principalmente quando um dos polos do litígio tem poder econômico, seja pessoa, empresa ou órgão estatal.

\begin{abstract}
De fato, com o elevado custo do processo judicial, parcela significativa da população não pode arcar com as despesas advindas das custas processuais, honorários advocatícios, perícias etc., principalmente quando no outro pólo do litígio a parte tem poder econômico, seja pessoa, empresa ou órgão estatal. A igualdade formal, para ser eficaz precisa, portanto, se perfazer em associação com uma igualdade material ainda que utópica. ${ }^{24}$
\end{abstract}

Ademais, quanto menor o valor discutido em juízo, maior é o custo do processo, que também pode ser agravado com a demora na solução jurisdicional, pois, consequentemente haverá aumento considerável nos custos, obrigando, até mesmo, os economicamente

\footnotetext{
${ }^{20}$ SANTOS, Boaventura de Sousa. Pela mão de Alice: o social e o político na pós-modernidade. 9. ed. São Paulo: Cortez, 2003. p. 167.

${ }^{21}$ CAPPELLETTI, Mauro; GARTH, Bryant. Acesso à justiça. Tradução Ellen Gracie Northfleet. Porto Alegre: Fabris, 2002. p. 15-16

${ }^{22}$ SANTOS, Boaventura de Sousa. Pela mão de Alice: o social e o político na pós-modernidade. 9. ed. São Paulo: Cortez, 2003. p. 168.

${ }^{23}$ CAPPELLETTI, Mauro; GARTH, Bryant. Acesso à justiça. Tradução Ellen Gracie Northfleet. Porto Alegre: Fabris, 2002. p. 21.

${ }^{24}$ MATTOS. Fernando Pagani. Acesso à justiça: um princípio em busca da efetivação. Curitiba: Juruá, 2009 . p.76.
} 
hipossuficientes a aceitar acordo muito aquém do que de direito, ou até mesmo abandonar a causa. $^{25}$

Marc Galanter traz, ainda, as figuras dos litigantes "eventuais" e "habituais", como obstáculo a efetividade ao acesso à justiça. Para o autor, àqueles que se utilizam frequentemente do poder judiciário para valer-se de seus direitos possuem prevalência sobre aqueles que pouco se utilizam, uma vez que a maior experiência com o direito proporciona maior planejamento do litígio; possui economia de escala já que tem mais casos; possui uma maior oportunidade em ter relações informais com os decisores; pode-se diluir os riscos da demanda por ter mais casos; pode testar diversas estratégias em determinados casos, a fim de garantir expectativa favorável em casos futuros. ${ }^{26}$

Para Milton Santos, a resolução dos conflitos de modo judicial é cara e dispendiosa, sendo que, esta onerosidade abrange além das custas judiciais todas as despesas que envolvem o processo, bem como, o abalo emocional das partes à espera da decisão o que também acaba por afastar cidadão do judiciário:

\begin{abstract}
Além dos intricados labirintos que os processos judiciais devem percorrer lentamente, as chamadas custas desses processos desanimam até mesmo os que dispõem de alguns recursos financeiros. Para os pobres, a justiça é mais barreira intransponível que uma porta aberta. As manifestações de desalento e descrença quando uma ofensa ao direito é constatada são muitas vezes mais numerosas que as palavras ou gestos de confiança, ou, ao menos, respeito pelo aparelho judicial-policial. Além desses entraves propriamente processuais, contêm-se, no lado ideológico ou sociológico, com a inadequação ou desatualização em que se encontram muito dos que são, oficialmente, guardiões da justiça e da paz social. ${ }^{27}$
\end{abstract}

Para muitos doutrinadores, a exemplo de Mauro Cappelletti e Bryant Garth, a figura do advogado é indispensável para as análises das legislações e para ajuizamento de ações, para tanto, defendem como essencial a assistência judiciária gratuita àqueles que necessitam ${ }^{28}$, como é o caso do artigo $5^{\circ} \operatorname{LXXIV}^{29}$ da Constituição Federal de 1988, que garante a assistência judiciária gratuita aos que comprovarem insuficiência de recursos, assegurada pelo Estado

\footnotetext{
${ }^{25}$ CAPPELleTti, Mauro; GARTH, Bryant. Acesso à justiça. Tradução Ellen Gracie Northfleet. Porto Alegre: Fabris, 2002. p. 19-20.

${ }^{26}$ GALANTER, Marc, Afterword: Explaining Litigation. In CAPPELLETTI, Mauro; GARTH, Bryant. Acesso à justiça. Tradução Ellen Gracie Northfleet. Porto Alegre: Fabris, 1988. p.25.

${ }^{27}$ SANTOS. Milton. O espaço do cidadão. São Paulo: Nobel, 2000. p. 68

${ }^{28}$ CAPPELLETTI, Mauro; GARTH, Bryant. Acesso à justiça. Tradução Ellen Gracie Northfleet. Porto Alegre: Fabris, 2002. p. 30-47

29 “Art. $5^{\circ}$ [...] LXXIV - o Estado prestará assistência jurídica integral e gratuita aos que comprovarem insuficiência de recursos."
} 
Democrático de Direito com base em diversos da igualdade, acesso à justiça e devido processo legal. ${ }^{30}$

No Brasil, a função jurisdicional do Estado para que concretize o acesso à justiça à população carente, é exercida pela Defensoria Pública, de acordo com o artigo 134 da Constituição Federal de 1988 e a Lei Complementar nº 80 de 1994.

Destaca-se também o papel dos Núcleos de Assistência Jurídica das faculdades de direito, que contribuem para a minimização do problema do acesso à justiça mediante o atendimento da população hipossuficiente. ${ }^{31}$ Assim, tanto a Defensoria Pública quanto a dativa são essenciais para a efetivação do acesso à justiça, atendendo os hipossuficientes.

Além das custas judiciais, a morosidade da prestação jurisdicional constitui outra barreira ao acesso à justiça. Tal morosidade, no entanto, por diversas vezes é ocasionada pelas chicanas processuais, ou seja, meios utilizados pelo advogado a fim de protelar ou criar embaraços no andamento processual. ${ }^{32}$

A possibilidade de retardar o andamento processual através de meios ardilosos, ou ainda de usar o duplo grau de jurisdição, não para sanar alguma irregularidade, mas como meio protelatório, revela a necessidade de uma reorganização na legislação, a fim de limitar o número de recursos e assim desestimular meios protelatórios. Neste sentido a legislação vem, ainda que lentamente avançando, conforme artigo 1026 , $\$ 2^{\circ}$ do $\mathrm{CPC}^{33}$, que prevê multa àqueles que opuserem Embargos de Declaração protelatórios.

Segundo Cândido Rangel Dinamarco, para se alcançar a afetividade do processo, este deve cumprir integralmente com a sua função sócio-político-jurídica, atingindo assim, todas as finalidades institucionais, ou seja, o processo deve proporcionar a quem tem um direito, tudo

\footnotetext{
${ }^{30}$ MATTOS. Fernando Pagani. Acesso à justiça: um princípio em busca da efetivação. Curitiba: Juruá, 2009. p. 94

${ }^{31}$ MATTOS. Fernando Pagani. Acesso à justiça: um princípio em busca da efetivação. Curitiba: Juruá, 2009. p. 102

${ }^{32}$ MATTOS. Fernando Pagani. Acesso à justiça: um princípio em busca da efetivação. Curitiba: Juruá, 2009. p. 79.

33 “Art. 1.026. Os embargos de declaração não possuem efeito suspensivo e interrompem o prazo para a interposição de recurso. [...] $\S 2^{\circ}$ Quando manifestamente protelatórios os embargos de declaração, o juiz ou o tribunal, em decisão fundamentada, condenará o embargante a pagar ao embargado multa não excedente a dois por cento sobre o valor atualizado da causa."
} 
aquilo que ele tem o direito de obter ${ }^{34}$. Para tanto, cabe também ao Poder Judiciário um pronunciamento jurisdicional aquedado, simplificado e célere. ${ }^{35}$ Neste sentido Ernani Fidelis Santos alerta que "se o direito existe para garantir o gozo de um bem da vida, o tempo poderá frustrar lhe a própria existência, quando, em virtude dele, não puder ser exercida a contento"36.

Em que pese haver entendimento doutrinário no sentido de que o julgamento antecipado da lide ocasiona empecilho ao acesso à justiça, este é devidamente autorizado pelo artigo 355, I do Código de Processo Civil ${ }^{37}$.

Evidente que o julgamento antecipado da lide privilegia outros princípios, tais como da celeridade, duração razoável do processo economia processual esculpidos no artigo $5^{\circ}$, LXXVIII da $\mathrm{CF}^{38}$. Portanto, há de verificar que o acesso à justiça não constitui apenas na possibilidade de ingresso no Judiciário, mas também a garante um processo célere com respeito aos princípios processuais.

Oliveira, discorrendo acerca do princípio da razoável duração do processo, assevera que:

A razoável duração do processo insere-se como um acréscimo ao princípio do acesso à justiça, ampliando-o. Denota, a partir da recém aprovada emenda, a preocupação do legislador constitucional com a temática do tempo na prestação da tutela jurisdicional, nos Estados que se constituem em Estado Democrático de Direito. Tem como fundamento o pleno exercício da cidadania e o respeito à dignidade da pessoa humana, atributos que consolidam a compreensão dos princípios inerentes aos Direitos Humanos. $^{39}$

O princípio da celeridade é indispensável para o cumprimento da tarefa atribuída ao Poder Judiciário $^{40}$, outrossim, o julgamento antecipado da lide, deve ser analisado caso a caso

\footnotetext{
${ }^{34}$ DINAMARCO, Cândido Rangel. A instrumentalidade do processo. São Paulo: Malheiros, 1999. p. 270.

35 PACHECO, José da Silva. Evolução do processo civil brasileiro: desde as origens até o advento do novo milênio. Rio de Janeiro: Renovar, 1999. p. 394.

${ }^{36}$ SANTOS, Ernani Fidelis. Novos perfis do processo civil brasileiro. Belo Horizonte: Del Rey, 1996. p. 17-18.

37 “Art. 355. O juiz julgará antecipadamente o pedido, proferindo sentença com resolução de mérito, quando: I não houver necessidade de produção de outras provas; [...]"

38 “Art. $5^{\circ}$ Todos são iguais perante a lei, sem distinção de qualquer natureza, garantindo-se aos brasileiros e aos estrangeiros residentes no País a inviolabilidade do direito à vida, à liberdade, à igualdade, à segurança e à propriedade, nos termos seguintes: [...] LXXVIII a todos, no âmbito judicial e administrativo, são assegurados a razoável duração do processo e os meios que garantam a celeridade de sua tramitação."

${ }^{39}$ OLIVEIRA. Luiz Flávio de. A Reforma do Poder Judiciário. Coord. Jorge Luiz de Almeida. In: A Razoável Duração do Processo na Perspectiva dos Direitos Humanos. Millennium, Campinas, 2006, p. 103.

${ }^{40}$ WATANABE, Kazuo. Juizado Especial de Pequenas Causas: Lei 7.244, de 07 de novembro de 1984. São Paulo: Revista dos Tribunais, 1985. p 109.
} 
pelo juiz da causa, consoante preceitua o artigo 370 do $\mathrm{CPC}^{41}$. Neste sentido Humberto Theodoro Junior registra que além do interesse da parte, em jogo na lide, há o interesse estatal, em que a lide seja composta de forma justa e segundo as regras do direito. ${ }^{42}$ Assim, caso o processo necessite de ampla dilação probatória, não se cogitaria o julgamento antecipado, correndo-se o risco de lesionar o acesso à justiça.

Outro empecilho determinante à acessibilidade da justiça é a capacidade jurídica pessoal, que está relacionada às vantagens de recursos financeiros, porém de ordem social e cultural, e se caracterizam pela ausência ou insuficiência do acesso à educação e pelo ao meio e status social em que a pessoa vive. ${ }^{43}$ Tais cidadãos tendem a conhecer menos seus direitos e, por consequência, possui mais dificuldade em reconhecer o problema jurídico que lhes afeta, porém, ainda que entenda que o problema é de ordem jurídica, hesita em recorrer ao poder judiciário para soluciona-lo. ${ }^{44}$ Assim, há necessidade de políticas públicas relativas à criação de um sistema educacional para que todos tenham as mesmas oportunidades e possibilidades de crescimento intelectual, social e econômico.

Horácio Wanderley Rodrigues lembra, ainda, que a tradição cultural brasileira, coloca o magistrado como um ser superior, distancia o povo simples da busca da justiça. O cidadão comum, regra geral, vê o poder judiciário como um objeto distante, inacessível, que não pertence à sua realidade. ${ }^{45}$ Outrossim, tribunais localizados em grandes centros e construções luxuosas intimidam os hipossuficientes, e, embora em menor grau, o mesmo ocorre com relação à própria figura do advogado.

Assim, elementos simbólicos, psicológicos e ideológicos também podem se tornar empecilhos ao acesso à justiça, tais como sentimentos de inferioridade, medo dos profissionais

\footnotetext{
41 “Art. 370. Caberá ao juiz, de ofício ou a requerimento da parte, determinar as provas necessárias ao julgamento do mérito. Parágrafo único. O juiz indeferirá, em decisão fundamentada, as diligências inúteis ou meramente protelatórias."

42 JÚNIOR, Humberto Theodoro. Teoria Geral do Direito Processual Civil e Processo de Conhecimento. 55. Ed. Rio de Janeiro: Forense, 2014. p. 297.

${ }^{43}$ CAPPELLETTI, Mauro; GARTH, Bryant. Acesso à justiça. Tradução Ellen Gracie Northfleet. Porto Alegre: Fabris, 2002. p. 22.

${ }^{44}$ SANTOS, Boaventura de Sousa. Pela mão de Alice: o social e o político na pós-modernidade. 9. ed. São Paulo: Cortez, 2003. p. 170.

${ }^{45}$ RODRIGUES, Horácio Wanderley. Acesso à Justiça: dimensões jurídico-processuais no contexto brasileiro da última década. [Trabalho elaborado para o concurso para professor titular da disciplina de teoria geral do processo da Universidade Federal de Santa Catarina]. Florianópolis, 1993. p. 44.
} 
do direito, e que, em diversas situações, revelam o distanciamento da maioria da população à realidade. ${ }^{46}$

Os direitos difusos, coletivos e individuais homogêneos constituem outro grande entrave ao acesso à justiça, uma vez, que o mundo contemporâneo se caracteriza por uma crescente ampliação desses direitos, e esse cenário conflita com o ordenamento jurídico pátrio, que se encontra estruturado, fundamentalmente, sobre a ideia do indivíduo como titular de direitos, numa reprodução dos valores clássicos do liberalismo do século XVIII. ${ }^{47}$

\title{
3. A TUTELA COLETIVA DE INDIVIDUAIS HOMOGÊNEOS E OS DIREITOS DA PERSONALIDADE
}

A tutela de direitos difusos, coletivos e individuais homogêneos, sob a égide do princípio do livre acesso à justiça, está ligada a ideia de que todos os cidadãos podem ter suas pretensões de direito analisadas pelo Poder Judiciário, no entanto, ainda se discute na doutrina e na jurisprudência questões formais acerca da possibilidade de utilização indistinta da Ação Civil Pública para efetivar a proteção destes interesses.

A definição de direitos difusos, coletivos e individuais homogêneos é trazida pelo Código de Defesa do Consumidor.

\begin{abstract}
Art. 81. A defesa dos interesses e direitos dos consumidores e das vítimas poderá ser exercida em juízo individualmente, ou a título coletivo.

Parágrafo único. A defesa coletiva será exercida quando se tratar de:

I - interesses ou direitos difusos, assim entendidos, para efeitos deste código, os transindividuais, de natureza indivisível, de que sejam titulares pessoas indeterminadas e ligadas por circunstâncias de fato;

II - interesses ou direitos coletivos, assim entendidos, para efeitos deste código, os transindividuais, de natureza indivisível de que seja titular grupo, categoria ou classe de pessoas ligadas entre si ou com a parte contrária por uma relação jurídica base;
\end{abstract}

\footnotetext{
${ }^{46}$ MATTOS. Fernando Pagani. Acesso à justiça: um princípio em busca da efetivação. Curitiba: Juruá, 2009. p. 87

${ }^{47}$ RODRIGUES, Horácio Wanderley. Acesso à Justiça: Dimensões jurídico-processuais no contexto brasileiro da última década. [Trabalho elaborado para o concurso para professor titular da disciplina de teoria geral do processo da Universidade Federal de Santa Catarina]. Florianópolis, 1993. p. 38
} 
III - interesses ou direitos individuais homogêneos, assim entendidos os decorrentes de origem comum. ${ }^{48}$

Tem-se, assim, que os interesses ou direitos difusos são os de natureza indivisível em que são titulares pessoas indeterminadas e ligadas por circunstâncias de fato; os coletivos, também de natureza indivisível de que seja titular grupo, categoria ou classe de pessoas ligadas entre si ou com a parte contrária por uma relação jurídica base; e os individuais homogêneos, entendidos serem decorrentes de origem comum.

Ao refletir sobre os interesses em sentido amplo, Mauro Cappelletti e Brynt Garth lembram que tais direitos trazem consigo um problema básico em razão de sua natureza. Para eles, ou ninguém tem direito a corrigir a lesão a um interesse coletivo, ou o prêmio para qualquer indivíduo buscar essa correção é pequeno demais para induzi-lo a tentar uma ação ${ }^{49}$, tornando, assim, pouco vantajoso para o cidadão comum enfrentar a burocracia judicial. Porém, há inquietação quanto a natureza dos direitos individuais homogêneos, bem como quanto a possibilidade tutela conjunta de tais direitos.

Teori Zavascki, adverte que, com o advento do Código de Proteção e Defesa do Consumidor, que introduziu mecanismo especial para a defesa coletiva dos chamados direitos individuais homogêneos, passou-se a considerar tal categoria de direitos como espécies dos direitos coletivos e difusos, lançando-os todos eles em vala comum, como se lhes fossem comuns e idênticos os instrumentos processuais e as fontes normativas de legitimação para a sua defesa em juízo.

Segundo o autor, "o direito coletivo é designação genérica para as duas modalidades de direitos transindividuais: o difuso e o coletivo stricto sensu". Por outro lado, "os direitos individuais homogêneos são, simplesmente, direitos subjetivos individuais. A qualificação de homogêneos não altera nem pode desvirtuar essa sua natureza. ${ }^{50}$ Desta forma, a ideia de

\footnotetext{
${ }^{48}$ BRASIL. Lei $\mathrm{n}^{\circ}$ 8.078, de 11 de setembro de 1990. Dispõe sobre a proteção do consumidor e dá outras providências. Portal da Legislação, Brasília, DF, 11 set. 1990. Disponível em: www.planalto.gov.br. Acesso em: 01 ago. 2019.

${ }^{49}$ CAPPELLETTI, Mauro; GARTH, Bryant. Acesso à justiça. Tradução Ellen Gracie Northfleet. Porto Alegre: Fabris, 2002. p. 26

${ }^{50}$ ZAVASCKI, Teori Albino. Processo Coletivo: tutela de direitos coletivos e tutela coletiva de direitos, São Paulo: Editora Revista dos Tribunais, 2011, p. 34.
} 
homogeneidade teria como principal objetivo possibilitar o tratamento dos direitos individuais de forma coletiva. ${ }^{51}$

O emprego da terminologia "defesa coletiva" ou "tutela coletiva" de direitos individuais homogêneos trata do modo coletivo de tutela, ou seja, do instrumento de defesa, e não da qualificação coletiva do direito material tutelado. ${ }^{52}$ Ademais, a classificação dos direitos individuais homogêneos quanto ao aspecto subjetivo (titularidade do direito material), trazida por Antînio Gidi, arremata essa tese: "quanto a esse aspecto, não vemos como não atribuir a tais direitos o status de direitos subjetivos: direitos subjetivos difusos, direitos subjetivos coletivos, direitos subjetivos individuais homogêneos" ${ }^{\text {"53. }}$.

Segundo o Gidi, a possibilidade de defesa coletiva de direitos individuais decorre da expressa previsão legal "subjetivos individuais homogêneos", que representa uma ficção criada pelo direito positivo brasileiro com a finalidade única e exclusiva de possibilitar a proteção coletiva (molecular) de direitos individuais com dimensão coletiva (em massa)., ${ }^{, 54}$

Sendo assim, ao reconhecer o caráter subjetivo individual dos direitos individuais homogêneos, inexistência instrumentos legislativos para a tutela conjunta de tais direitos? Haver-se-ia necessário recorrer ao sistema tradicional de tutela dos direitos individuais prevista pelo Código de Processo Civil?

Sobre este aspecto, Zavascki reconhece que nos casos em que há prevalência do interesse público da tutela coletiva dos direitos individuais homogêneos, este deve prevalecer em detrimento dos interesses meramente privados.

[...] a lesão a certos direitos individuais homogêneos pode assumir tal grau de profundidade ou de extensão que acaba comprometendo também interesses sociais. Realmente, há certos interesses individuais, que, quando visualizados em seu conjunto, em forma coletiva e impessoal, têm a força de transcender a esfera de interesses puramente individuais e passar a representar, mais que a soma de interesses dos respectivos titulares, verdadeiros interesses da comunidade como um todo. ${ }^{55}$

\footnotetext{
${ }^{51}$ Em sentido contrário: DIDIER Jr, Fredie, ZANETI Jr., Hermes. Curso de Direito Processual Civil. vol. 4, 4. ed. Salvador: JusPodivm, 2009.

52 ZAVASCKI, Teori Albino. Processo Coletivo: tutela de direitos coletivos e tutela coletiva de direitos, São Paulo: Editora Revista dos Tribunais, 2011, p. 35.

${ }^{53}$ GIDI, Antônio. Coisa Julgada e Litispendência em ações coletivas. São Paulo: Saraiva, 1995, p. 22.

${ }^{54}$ GIDI, Antônio. Coisa Julgada e Litispendência em ações coletivas. São Paulo: Saraiva, 1995, p. 30.

55 ZAVASCKI, Teori Albino. Processo Coletivo: tutela de direitos coletivos e tutela coletiva de direitos, São Paulo: Editora Revista dos Tribunais, 2011, p. 47-48.
} 
O interesse social, que transcende o caráter individual do direito, confere uma natureza pública e coletiva. Nada obstante, isso não pode mascarar a característica individual do direito, podendo solicitar individualmente a providência jurisdicional, sem precisar aguardar a iniciativa dos legitimados para a tutela coletiva ${ }^{56}$, cabendo discussão em juízo, em caso de eventual discordância da prevalência do interesse público ao interesse privado

No Brasil, segundo a Lei no 7.347 de $1985^{57}$, a Ação Civil Pública é o instrumento processual de que podem se valer o Ministério Público e outras entidades legitimadas na defesa de interesses difusos, coletivos e individuais homogêneos, não podendo, a princípio, ser utilizada para a defesa de direitos e interesses disponíveis nem para interesses propriamente privados, salvo se puderem interessar a grupos, classes ou categorias de pessoas que se encontrem na mesma situação de fato e de direito, como no caso dos interesses individuais homogêneos. No entanto, ao se reconhecer a prevalência do interesse público da tutela coletiva dos direitos individuais homogêneos, poder-se-ia empregar a Ação Civil Pública.

A lei da ação civil pública (art. 21) remete a aplicação, no que couber, dos dispositivos do Código de Defesa do Consumidor, que, por sua vez, prevê a tutela coletiva dos direitos individuais homogêneos. Assim, se o próprio dispositivo legal que dispõe sobre a ação civil pública prevê a aplicação da hipótese prevista no art. 81, III, do CDC, não se podendo admitir, desta forma, restrições para tutela coletiva desses interesses em sede da via processual prevista na lei $7.347 / 85$.

Ainda, no caso do uso deste instrumento jurídico, a indivisibilidade ou não do direito torna-se irrelevante, uma vez que em caso de procedência da ação, a sentença produzirá efeitos erga omnes beneficiando todo o grupo ou a classe substituída, seja o direito difuso, coletivo ou individual homogêneo.

\footnotetext{
${ }^{56}$ ARAUJO FILHO, Luiz Paulo da Silva, Ações Coletivas: A tutela jurisdicional dos direitos individuais homogêneos, Rio de Janeiro: Editora Forense, 2000.

${ }^{57}$ BRASIL. Lei ${ }^{\circ}$ 7.347, de 24 de julho de 1985. Disciplina a ação civil pública de responsabilidade por danos causados ao meio-ambiente, ao consumidor, a bens e direitos de valor artístico, estético, histórico, turístico e dá outras providências. Portal da Legislação, Brasília, DF, 24 jul. 1985. Disponível em: http://www.planalto.gov.br/ccivil_03/leis/L7347Compilada.htm. Acesso em: 01 ago. 2019.
} 


\section{CONSIDERAÇÕES FINAIS}

O presente estudo traz as dificuldades do acesso à justiça e meios para efetivação deste acesso, a fim de alcançar o maior número possível de indivíduos. Foi possível verificar que são numerosos os fatores apontados como impeditivos para o acesso à justiça e são igualmente abundantes as teorias que buscam resolver ou minimizar esses efeitos.

Diante das propostas, destacou-se a implementação de instrumentos processuais adequados, procedimentos simplificados, celeridade, a assistência judiciária gratuita como forma de contornar os problemas econômicos etc. Porém, o problema dos entraves à efetivação da justiça estende-se também aos direitos da personalidade, como direitos subjetivos que têm por objeto os bens e valores essenciais da pessoa, no seu aspecto físico, moral e intelectual. A dificuldade se acentua quando se observa os constantes avanços da sociedade, e com isso, a ampliação destes direitos.

Neste sentido, buscou-se analisar os direitos individuais homogêneos e sua natureza jurídica de direitos subjetivos individuais, que foram convertidos por uma ficção jurídica em direitos coletivos lato sensu para tutelá-los judicialmente de forma mais efetiva.

Considerando isso, foi possível verificar que esses direitos individuais homogêneos, visto com interesse social, dentre os quais também se acomodar direitos da personalidade, pode se efetivar pela via da prestação jurisdicional coletiva ou individual.

Por fim, analisou-se o que dispõe o Código de Defesa do Consumidor e a lei sobre ação civil pública, entendendo que tais normas são complementares e integram o sistema processual coletivo, não devendo ser interpretadas de forma restritiva, sob pena de comprometer a própria efetividade da tutela coletiva de direitos. E, neste sentido, não é necessário novos ritos para garantir o acesso à justiça, porém, deve-se perceber a nova realidade, operar e aplicar instrumentos que estão ao alcance e assim possibilitar ao cidadão a efetividade do judiciário. 


\section{REFERÊNCIAS BIBLIOGRÁFICAS}

ARAUJO FILHO, Luiz Paulo da Silva, Ações Coletivas: A tutela jurisdicional dos direitos individuais homogêneos, Rio de Janeiro: Editora Forense, 2000.

BRANDÃO, Paulo de Tarso. Ações Constitucionais: novos direitos e Acesso à Justiça. Florianópolis: Habitus, 2001.

BRANDÃO, Paulo de Tarso; MARTINS, Douglas Roberto. Julgamento antecipado da lide, direito à prova e Acesso à Justiça. In: ROSA, Alexandre Moraes da (Org.). Para um direito democrático: diálogos sobre paradoxos. São Jose: Conceito, 2006.

BRASIL. Constituição (1988). Constituição da República Federativa do Brasil. Brasília, DF: Senado Federal.

BRASIL. Lei $\mathrm{n}^{\mathrm{o}}$ 7.347, de 24 de julho de 1985. Disciplina a ação civil pública de responsabilidade por danos causados ao meio-ambiente, ao consumidor, a bens e direitos de valor artístico, estético, histórico, turístico e dá outras providências. Portal da Legislação,
Brasília,
$\mathrm{DF}$,
24
jul.
1985.
Disponível
em:

http://www.planalto.gov.br/ccivil_03/leis/L7347Compilada.htm. Acesso em: 01 ago. 2019.

BRASIL. Lei $\mathrm{n}^{\circ}$ 8.078, de 11 de setembro de 1990. Dispõe sobre a proteção do consumidor e dá outras providências. Portal da Legislação, Brasília, DF, 11 set. 1990. Disponível em: www.planalto.gov.br. Acesso em: 01 ago. 2019.

CAPPELlETTI, Mauro; GARTH, Bryant. Acesso à justiça. Tradução de Ellen Gracie Northfleet. Porto Alegre: Fabris, 2002.

DIDIER Jr, Fredie, ZANETI Jr., Hermes. Curso de Direito Processual Civil. vol. 4, 4. ed. Salvador: JusPodivm, 2009.

DINAMARCO, Cândido Rangel. A instrumentalidade do processo. São Paulo: Malheiros, 1999. p. 270.

GALANTER, Marc, Afterword: Explaining Litigation. In CAPPELLETTI, Mauro; GARTH, Bryant. Acesso à justiça. Tradução Ellen Gracie Northfleet. Porto Alegre: Fabris, 1988.

GIDI, Antônio. Coisa Julgada e Litispendência em ações coletivas. São Paulo: Saraiva, 1995.

JABORANDY, Clara Cardoso Machado; NEJAIM, América Cardoso Barreto Lima. O diálogo da mediação: uma garantia de acesso à ordem jurídica humanizada. Revista Juris Poiesis, Rio de Janeiro. Vol. 21, n. 26, 2018, p. 153 - 173. Disponível em http://periodicos.estacio.br/index.php/jurispoiesis/article/viewFile/5737/47965109. Acesso em: 30 jul. 2019.

JÚNIOR, Humberto Theodoro. Teoria Geral do Direito Processual Civil e Processo de Conhecimento. 55. Ed. Rio de Janeiro: Forense, 2014. 
LAFER, Celso. A reconstrução dos direitos humanos: um diálogo com o pensamento de Hannah Arendt. São Paulo: Companhia das Letras, 2009.

MARTINS, Pedro Batista. Acesso à justiça. In: MARTINS, Pedro Batista et al. Aspectos fundamentais da lei da arbitragem. Rio de Janeiro: Forense, 1999.

MATTOS. Fernando Pagani. Acesso à justiça: um princípio em busca da efetivação. Curitiba: Juruá, 2009. MORAES, Maria Celina Bodin. Ampliando os direitos da personalidade. In: 20 anos da Constituição Cidadã de 1988: efetivação ou impasse institucional. (Org.) José Ribas Vieira. Rio de Janeiro: Forense, 2008. Disponível em: https://www.academia.edu/9689598/Ampliando_os_direitos_da_personalidade. Acesso em: 29 mar. 2019.

OLIVEIRA, José Sebastião de; ROSA, Angélica Ferreira. O acesso à justiça: realidade ou ficção, neste início de século XXI? Revista Jurídica Cesumar - Mestrado, v. 16, n. 2, maio/ago. 2016 - ISSN 1677-6402.

OLIVEIRA. Luiz Flávio de. A Reforma do Poder Judiciário. Coord. Jorge Luiz de Almeida. In: A Razoável Duração do Processo na Perspectiva dos Direitos Humanos. Millennium, Campinas, 2006, p. 103.

PACHECO, José da Silva. Evolução do processo civil brasileiro: desde as origens até o advento do novo milênio. Rio de Janeiro: Renovar, 1999.

PAROSKI, Mauro Vasni. Direitos fundamentais e acesso à justiça na constituição. São Paulo: LTr, 2008, p. 138

MORAES, Humberto Pena de; SILVA, José Fontenelle Teixeira da. Assistência judiciária: sua gênese sua história e a função protetiva do Estado. 2. ed. Rio de Janeiro: Líber Juris, 1984.

RAMOS, Glaugo Gumerato. Realidade e perspectivas da assistência jurídica ao necessitado no Brasil. Revista do Advogado. São Paulo. n. 59, 2000.

RODRIGUES, Horácio Wanderley. Acesso à Justiça: dimensões jurídico-processuais no contexto brasileiro da última década. [Trabalho elaborado para o concurso para professor titular da disciplina de teoria geral do processo da Universidade Federal de Santa Catarina]. Florianópolis, 1993.

SANTOS, Boaventura de Sousa. Pela mão de Alice: o social e o político na pós-modernidade. 9. ed. São Paulo: Cortez, 2003. p. 167.

SANTOS, Ernani Fidelis. Novos perfis do processo civil brasileiro. Belo Horizonte: Del Rey, 1996.

SANTOS. Milton. O espaço do cidadão. São Paulo: Nobel, 2000.

SILVA, Adriana dos Santos. Acesso à justiça e arbitragem: um caminho para a crise do judiciário. São Paulo: Manole, 2005. 
WATANABE, Kazuo. Juizado Especial de Pequenas Causas: Lei 7.244, de 07 de novembro de 1984. São Paulo: Revista dos Tribunais, 1985.

ZAVASCKI, Teori Albino. Processo Coletivo: tutela de direitos coletivos e tutela coletiva de direitos, São Paulo: Editora Revista dos Tribunais, 2011.

Data de Submissão: 01/08/2019

Data de Aceite: 12/12/2019 